\title{
Component Analysis of Odor Components in Food Waste Treatment
}

\author{
Wei $Q u^{1}$, Aihua Song2 ${ }^{2}$ Yongle Shan ${ }^{*}$, Rui Wang1* \\ ${ }^{1}$ Shandong Academy of Occupational Health and Occupational Medicine, Jinan, China \\ ${ }^{2}$ Environment Protection Monitoring Station of Tianqiao District, Jinan, China \\ Email: shanyongle@163.com, ${ }^{*}$ 13075308745@163.com
}

Received 24 May 2015; accepted 6 July 2015; published 13 July 2015

Copyright (C) 2015 by authors and Scientific Research Publishing Inc.

This work is licensed under the Creative Commons Attribution International License (CC BY).

http://creativecommons.org/licenses/by/4.0/

(c) (i) Open Access

\begin{abstract}
Purpose: To analyze the odor components in food waste treatment process. Method: Cold trap enrichment-GC/MS technology was used to determine the component. Result: The detection results showed that the levels of odorant concentrations from the main processing units were ranked in the order of: temperature sterilization device $>$ oil-water separator $>$ anaerobic fermenter $>$ separation equipment $>$ unloading area. Oxygenated organic compounds were the main components. Conclusion: Ethanol, hydrogen sulfide, dimethyl disulfide, ammonia, limonene were characteristic pollutants in the unloading areas and separation equipment; ethanol, methyl mercaptan, hydrogen sulfide, dimethyl disulfide, limonene were characteristic pollutants in the temperature sterilization device and oil-water separator; ethanol, hydrogen sulfide, dimethyl disulfide, p-diethylbenzene, limonene were characteristic pollutants in the anaerobic fermenter.
\end{abstract}

\section{Keywords}

Component Analysis, Characteristic Pollutant, Food Waste Treatment, Odor Pollutants

\section{Introduction}

With rapid progress of living standard and city restaurant industry, the amount of daily food waste generates over 20 thousand tons in China [1]. Food waste is the characteristic of putrescibility, high moisture content, high organic matter, which makes it have the typical duplicity of resource and pollution [2]. During the process of collection, transportation and disposal, food waste usually causes secondary pollution, especially $\mathrm{NH}_{3}$, VOCs. To provide theoretical basis for odor pollution prevention and management, this study took a typical food waste disposal enterprise in Jinan as the object, screened and preliminarily determined odor characteristics of pollutants.

*Corresponding author. 


\section{Collection and Analysis of Samples}

\subsection{Sampling Points Set}

We found the odor source mainly came from the discharge, high temperature sterilization, sorting, oil-water separation, anaerobic fermentation units. Samples were collected and analyzed for each unit. Sampling time: April 11th - 13th, 2014; sampling site temperature: $11.4^{\circ} \mathrm{C}-14.5^{\circ} \mathrm{C}$; pressure: 101.1 - $101.4 \mathrm{kPa}$; wind speed: 0.5 - 1.1 $\mathrm{m} / \mathrm{s}$; humidity: $33.2 \%-46.7 \%$.

\subsection{Instruments and Apparatus}

GC9800 gas chromatography mass spectrometry (CHN); Markes Unity solid adsorption-thermal desorption (GBR); Entech canister sampling-cold trap concentration system (USA); Wosaite DR59C- $\mathrm{NH}_{3}$ portable ammonia detector $(\mathrm{CHN})$.

\subsection{Method for Samples Analysis}

The odor concentration analysis method of reference was "Air quality-Determination of odor-Triangle odor bag method” (GB/T14675-93). The analysis method for VOCs referenced USA EPATO-15.

\section{Composition and Characteristics of Odor}

\subsection{Composition and Content}

By quantitative analysis of samples, the food waste disposal device emissions were detected with 10 kinds of alkane, 4 olefin, 17 aromatic, 9 halogenated, 4 organic compounds containing oxygen, 3 sulphur compounds and 2 other compounds (ammonia and naphthalene). Furthermore, 41 kinds of pollutants were detected in unloading area, the concentration level was $5.37 \mathrm{mg} / \mathrm{m}^{3} ; 43$ kinds of pollutants were detected in high temperature sterilization device, the concentration level was $15.62 \mathrm{mg} / \mathrm{m}^{3}$; 42 kinds of pollutants were detected in sorting device, the concentration level was $8.31 \mathrm{mg} / \mathrm{m}^{3}$; 41 kinds of pollutants were detected in sorting device, the concentration level was $8.26 \mathrm{mg} / \mathrm{m}^{3}$; 43 kinds of pollutants in oil water separation device, the concentration level was 13.16 $\mathrm{mg} / \mathrm{m}^{3} ; 43$ kinds of pollutants in anaerobic fermentation device, the concentration level was $13.21 \mathrm{mg} / \mathrm{m}^{3}$.

\subsection{Analysis of Spectral Components}

In order to highlight the characteristics of pollution sources emissions, the odor concentration of pollutant emissions for each unit was normalized. By analyzing, we found that ethanol, ammonia, limonene were the main substance discharged from each unit of the food waste disposal system, its significant content covered the features of other pollutants component in the spectrum, so the materials mentioned above were not included in each unit component spectrum. Compared with other regions, unloading area was more easily leaking. The composition and content distribution of unloading area (concentration $\geq 0.10 \%$ ) were shown in Figure 1 .

As we can see, pollutants in the exhaust gas of each unit were basically the same. The material with the most significant normalized concentration was ethanol, followed by ammonia, limonene, dichloromethane and toluene, ethyl acetate, propane, carbon disulfide, isobutene etc. In addition, ammonia, dimethyl disulfide, hydrogen sulfide, carbon disulfide, methyl mercaptan were all the controlled materials of emission standards for odor pollutants in China [3].

\subsection{Characteristics of Pollutants}

The test sample odor concentration (dimensionless) showed the odor concentration in discharge area was 722; the high temperature sterilization device was 4130; the sorting device was 3067; the oil-water separation device was 2311; the anaerobic fermentation device was 2306. The stench was results of various substances. Usually, the main pollutants were the malodorous substance with higher diluted multiples, but we can't completely decided that odor substance with the highest diluted multiples made the biggest contribution [4]. Based on monitoring data and each substance olfactory threshold concentration, we screened the top 5 substances concentration and threshold dilution of each disposal unit in Table 1. 


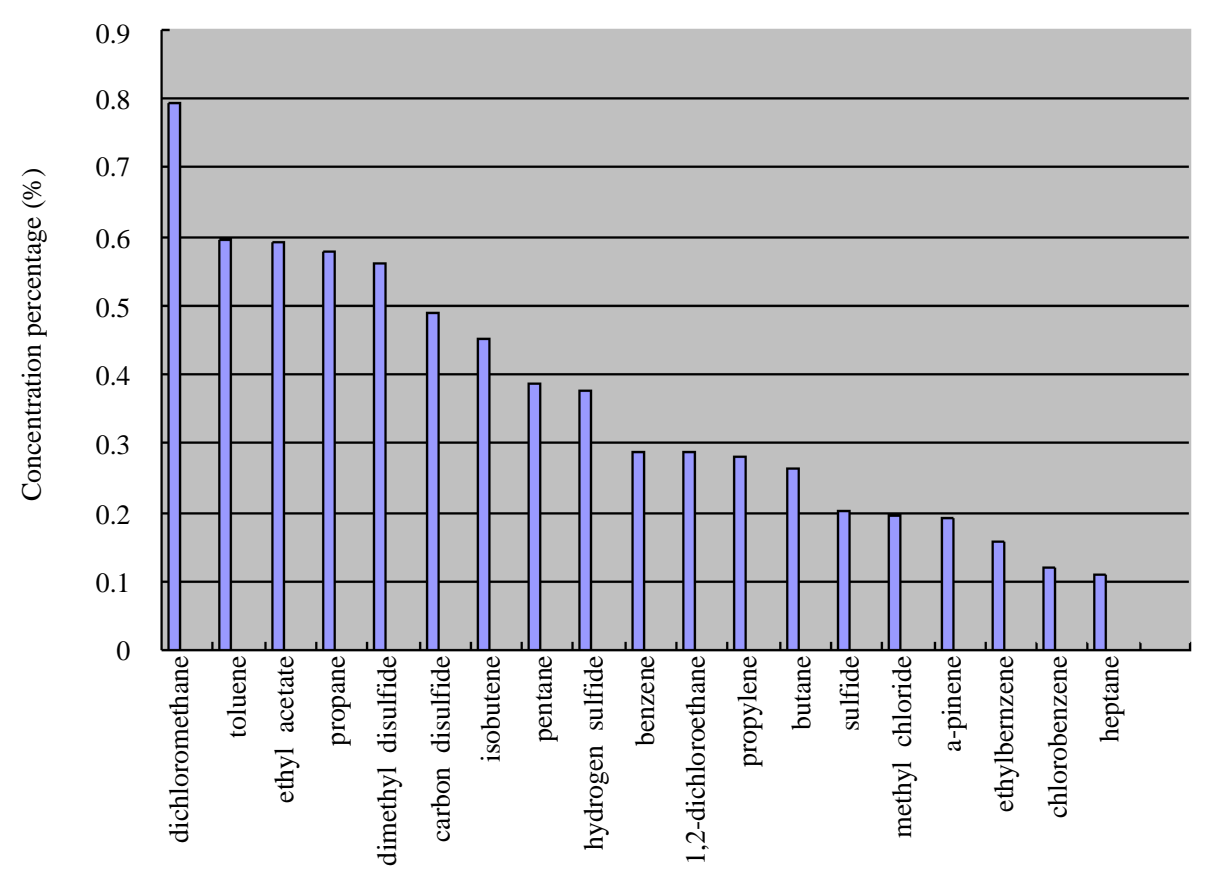

Figure 1. Pollutant component spectrum of unloading area.

Table 1. Top 5 substances concentration and threshold dilution of relevant unit.

\begin{tabular}{|c|c|c|c|c|}
\hline \multirow{2}{*}{ Odor Source } & \multicolumn{2}{|c|}{ Top 5 Substances Concentration } & \multicolumn{2}{|c|}{ Top 5 Threshold Dilution } \\
\hline & Substance Name & Concentration $\left(\mathrm{mg} / \mathrm{m}^{3}\right)$ & Substance Name & Threshold Dilution (dimensionless) \\
\hline \multirow{5}{*}{$\begin{array}{l}\text { Unloading } \\
\text { Area }\end{array}$} & ethanol & 4.66 & hydrogen sulfide & 48 \\
\hline & ammonia & 0.19 & dimethyl disulfide & 13 \\
\hline & limonene & 0.10 & ethanol & 8 \\
\hline & dichloromethane & 0.05 & limonene & 2 \\
\hline & toluene & 0.03 & ammonia & 1 \\
\hline \multirow{5}{*}{$\begin{array}{c}\text { High } \\
\text { Temperature } \\
\text { Sterilization }\end{array}$} & ethanol & 14.83 & methyl mercaptan & 69 \\
\hline & ammonia & 0.44 & hydrogen sulfide & 57 \\
\hline & limonene & 0.17 & ethanol & 27 \\
\hline & toluene & 0.05 & dimethyl disulfide & 4 \\
\hline & ethyl acetate & 0.03 & limonene & 4 \\
\hline \multirow{5}{*}{$\begin{array}{l}\text { Sorting } \\
\text { Device }\end{array}$} & ammonia & 7.67 & methyl mercaptan & 37 \\
\hline & ethanol & 0.44 & ethanol & 16 \\
\hline & dichloromethane & 0.11 & dimethyl disulfide & 13 \\
\hline & limonene & 0.07 & limonene & 3 \\
\hline & carbon disulfide & 0.04 & ammonia & 2 \\
\hline \multirow{5}{*}{$\begin{array}{l}\text { Oil-water } \\
\text { Separation } \\
\text { Device }\end{array}$} & ethanol & 12.52 & methyl mercaptan & 68 \\
\hline & ammonia & 0.18 & hydrogen sulfide & 53 \\
\hline & limonene & 0.13 & ethanol & 22 \\
\hline & ethyl acetate & 0.05 & dimethyl disulfide & 12 \\
\hline & toluene & 0.03 & limonene & 4 \\
\hline \multirow{5}{*}{$\begin{array}{l}\text { Anaerobic } \\
\text { Fermentation } \\
\text { Device }\end{array}$} & ethanol & 12.49 & hydrogen sulfide & 54 \\
\hline & ammonia & 0.37 & ethanol & 26 \\
\hline & limonene & 0.10 & dimethyl disulfide & 14 \\
\hline & dichloromethane & 0.04 & ammonia & 6 \\
\hline & toluene & 0.03 & limonene & 3 \\
\hline
\end{tabular}




\section{Conclusions}

Food waste has characteristic with high water content (60\% - 80\%), high organic matter proportion (more than 95\% dry matter), high salt content, less harmful substances and rich nutrition, which is very valuable for recycling [5]. The food waste treatment can not only provide us biogas energy, the residue can also be used as fertilizer [6], so the biological anaerobic fermentation technology has become a research focus. Through the analysis of the data, the results of our study were as follows:

1) Through the analysis of spectral components, ethanol emissions was the most significant during food waste disposal process, monitoring data show that ethanol normalized concentration was more than $85 \%$ of each unit, the reason may due to the alcohol residue and recycled products during anaerobic process. Ingredients of other pollutants were basically the same; the normalized concentration of ammonia, limonene, and dichloromethane was relatively high.

2) Each unit of food waste disposal facilities of anaerobic respectively detected 42 - 44 kinds of air pollutants, including alkane, olefin, benzeneseries, halogenated hydrocarbons, oxy-organics, sulfur compounds and other compounds, among which the concentration of oxy-organics was the highest.

Pollutant concentration level was in the order of: high temperature sterilization device > oil-water separation device $>$ anaerobic fermentation device $>$ sorting device $>$ unloading zone.

3) Through the analysis of odor concentration, high temperature sterilization device, separating device, oilwater separator, anaerobic fermentation device were obviously higher than those in the discharge area, which were the main odor source of this kind of enterprises. The total concentration level of pollutants exhaust gas separation device was not high, but the odor concentrations were relatively high, which due to a certain amount of extremely low odor threshold concentration hydrogen sulfide.

4) Preliminary identification conclusion of typical pollutants. For the unloading area and sorting device, the typical pollutants were ethanol, hydrogen sulfide, dimethyl disulfide, ammonia, limonene. The typical pollutants in high temperature sterilization, oil-water separation device were ethanol, methyl mercaptan, hydrogen sulfide, dimethyl disulfide, limonene; In anaerobic fermentation device, the typical pollutants were ethanol, hydrogen sulfide, dimethyl disulfide, limonene.

\section{Acknowledgements}

This research was supported by Shandong Province Natural Science Fund Project (ZR2012HL08); Shandong Province Science and Technology Research Projects (2013GSF11828); 2013 Technology Project of Major Accident Prevention Key Technologies for Safe Production (LAJK2013-112); Jinan Science and Technology Development Project (20130244).

\section{References}

[1] Cui, Y.W. and Chen, J.F. (2006) The Prospect of Resource Status and Prospect of Kitchen Waste. China Resources Comprehensive Utilization, 10, 31-32.

[2] Zhang, Q., Liu, L.F., Li, J., et al. (2011) Investigation and Analysis on the Present Situation of our Country's City of Kitchen Waste. China Resources Comprehensive Utilization, 10, 40-43.

[3] GB14554-93, Emission Standards for Odor Pollutants[s].

[4] Bao, J.L., Zou, K.H., Wang, L.S., et al. (2009) The Stench of Environmental Management and Pollution Control. Chinese Environment Science Press, Beijing, 6-7.

[5] Xu, J.L., Zhang, G.X., Xu, M.Y., et al. (2011) Research Progress of Microbial Technology Kitchen Waste Resource Utilization. Bulletin of Microbiology, 38, 928-933.

[6] Lee, D.H., Behera, S.K., Kim, J.W. and Park, H.-S. (2009) Methane Production Potential of Leachate Generated from Korean Food Waste Recycling Facilities: A Lab-Scale Study. Waste Management, 29, 876-882. http://dx.doi.org/10.1016/j.wasman.2008.06.033 